Calatayud A, Mangan J, Palacin R.

Connectivity to international markets: A multi-layered network approach. Journal of Transport Geography 2017, 61, 61-71.

\section{Copyright:}

(C) 2017. This manuscript version is made available under the CC-BY-NC-ND 4.0 license

DOI link to article:

https://doi.org/10.1016/j.jtrangeo.2017.04.006

Date deposited:

$01 / 06 / 2017$

Embargo release date:

05 May 2018

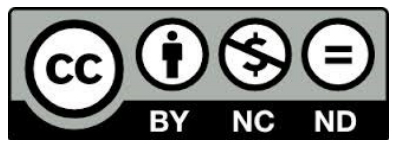

This work is licensed under a

Creative Commons Attribution-NonCommercial-NoDerivatives 4.0 International licence 


\title{
Connectivity to international markets: A multi-layered network approach
}

\author{
Calatayud A, Mangan J, Palacin R \\ Full reference: Calatayud A, Mangan J, Palacin R Connectivity to international markets: A multi-layered \\ network approach, Journal of Transport Geography, May 2017, volume 61, pp. 61-71
}

\begin{abstract}
Improving connectivity for freight movements between countries is increasingly a topic at the centre of the international trade and transport policy agendas. In spite of this, a method to asses a country's degree of connectivity to its international markets for freight is still missing. To close this gap, this paper proposes a multi-layered network approach that enables the assessment of: (i) the different factors that influence connectivity to international markets; and (ii) the extent to which a country's connections matter for its international trade activities. The international trade network and its 'support network' are analysed using network theory. The approach proposed is applied to the Americas, a region the relevant literature has not specifically focused on yet. It is expected that a comprehensive understanding and assessment of the determinants of connectivity for freight will contribute to guide and design more effective policies to remove barriers to international trade flows.
\end{abstract}

Keywords: connectivity, maritime transportation, international trade, networks.

\section{Introduction}

In the context of globalization, delocalization of production activities and the emergence of global value chains, enhancing connectivity is becoming critical as a means to overcome barriers to international trade and improve competitiveness (Arvis and Shepherd, 2015). Because of this, research on connectivity as a determinant of international trade flows has seen increasing attention from academia and policy-makers. While most of the available literature refers to a narrow definition of connectivity, with focus on transport services (Marquez-Ramos et al., 2011), a broader perspective on connectivity to international markets endorsed by the studies and programmes commissioned by policy-makers is emerging (ITF, 2012; xxx., 2016). Aside from transport services, this perspective includes infrastructure and trade facilitation procedures as important elements to assess connectivity to international markets. 'International markets' are defined as the geographic area of demand of commodities located in one or more countries abroad (Salvatore, 2002). Therefore, the term 'connectivity to international markets' refers, in general, to the capability of a given country to connect to countries demanding products from it, therefore ensuring a seamless movement of freight between countries. 
Despite increasing interest in this topic, a metric that takes into account the determinants of connectivity as suggested by the broader perspective is still missing. Instead, available connectivity metrics focus on the characteristics of transport services only. In addition, such metrics do not take into account whether and to what extent a country's connections influence the ability of exports to reach their destination markets. In contrast, a country's degree of connectivity is usually assessed in the context of transport networks only. An incomplete understanding on connectivity performance can misguide policy-makers and practitioners in their assessment of a country's degree of connectivity to international markets, the factors hindering it, and the actions needed to overcome any limitations. In this context, the premise proposed in this paper is that an approach that enables a more comprehensive assessment of the factors that influence a country's degree of connectivity, as well as the extent to which those connections matter for its international economic activities, can provide better guidance for policy-makers seeking to improve their country's connectivity to international markets.

The paper is organised as follows: Section 2 presents the literature review; Section 3 presents the methodology; Section 4 presents the results and discusses the implications for academic research and policy-making; and Section 5 presents the conclusions of this research.

\section{Literature review}

Literature in International and Transport Economics has shown that transport costs are a critical determinant of international trade. For example, Jacks and Pendakur (2010) and Bernhofen et al. (2016) showed that the introduction of containerization reduced transport costs and thus stimulated trade flows. Indeed, while in the past decade preferential agreements, multilateral negotiations, and unilateral trade liberalizations all significantly reduced tariff barriers, transport costs emerged as important deterrents to international trade. Given the prevalence of maritime transportation in international trade (UNCTAD, 2013), a large part of research focused on estimating the impact of port connectivity on international trade flows as a result of, for example, liner shipping route structure, equipment structure, and service structure (Marquez-Ramos et al., 2011). Available studies suggested that connectivity had a significant effect on transport costs-(Wilmsmeier and Martinez-Zarzoso 2010); that trade routes more centrally located in the maritime liner service network had lower average transport costs and higher trade flows (Marquez-Ramos et al., 2011); and that - together with distanceconnectivity was an important variable explaining the geographical patterns of trade flows (Guerrero et al., 2016).

Research on connectivity as a determinant of international trade flows has seen increasing attention not only from academia but also from policy-makers. In the context of globalization, delocalization of production activities and the emergence of global value chains, enhancing connectivity is becoming critical as a means to overcome barriers to international trade and improve competitiveness. For example, in its 2012 Annual Summit, the International Transport Forum (ITF) included among its main recommendations the need to increase "connectivity across borders" by enhancing infrastructure, increasing information sharing and providing the harmonisation and standardisation needed to smooth 
border crossing and reduce transit time (ITF, 2012, p. 30). National governments and international organisations have supported reports, master plans and programmes aimed at enhancing connectivity to international markets, evidencing policy-makers' growing interest in this subject (APEC, 2010; ASEAN, 2010). According to xxx (2016), available literature not always refers to the concept of connectivity with the same meaning. Instead, through a systematic literature review they suggest that, in the context of international trade, connectivity is frequently defined in three different ways: (1) a narrow definition focused on the availability and characteristics of infrastructure and transport services; (2) a broader definition that, apart from infrastructure and transportation, also includes trade facilitation procedures; and (3) a supply chain management definition that refers to the degree of information sharing among supply chain partners. In addition, a body of literature distinguishes between the concepts of connectivity and accessibility. Although tightly related, accessibility can be defined as the ability to be reached by others, measured in terms of cost and time (Salgado and Cea, 2012; Redondi et al., 2013). Instead, connectivity is more related to the configuration and characteristics of infrastructure and transport services, as a result of which nodes obtain different positions within a network and access to other nodes in the network (Mishra et al., 2012).

In line with the different definitions of connectivity present in the literature, a variety of metrics have been developed and applied to assess a country's degree of connectivity. Using Graph and Network metrics, literature in the fields of Transport Economics and Geography has estimated countries' connectivity based on the characteristics of transport networks. Indeed, connectivity is a network metric and can only be understood in the context of a network and its characteristics. In Graph and Network Theories, connectivity is defined as whether and how nodes are connected to one another through the network (Newman, 2003). In other words, connectivity refers to how easy it is to reach the network from a given node and the opportunity for connections (available links) that the node offers (Paleari et al., 2009). The use of network analysis in transportation geography has a long tradition (Garrison, 1960). In the past ten years, the research in this area has been advanced by developments in information technology, which spurred the timeliness and amount of data available, new research questions, and improved theoretical models (Gaile and Willmott, 2004). Together with GIS (Thill, 2000) and modelling (Sheppard, 2000), network analysis is one of the major topics of contemporary transportation geography (Gaile and Willmott, 2004).

Literature in the field of Maritime Transportation has applied connectivity metrics to explore the characteristics of shipping networks. Ports and ships movements are used to build adjacency matrices and study network topology (Hu and Zhu, 2009). Different network metrics that take into account the quantity - the number - of connections have been used to understand local connectivity (that of a specific port or group of ports) and global connectivity in the network. Among these are degree and degree centrality, network density or beta index, alpha and gamma indices, and betweenness centrality (Ducruet et al., 2010). These metrics have been useful to show that the container shipping network is a 'scale-free' network, where a limited number of nodes are highly connected and links among nodes are distributed according to a power-law distribution (Kaluza et al., 2010). The 'scale-free' characteristic reflects the hub-and-spoke organization of liners shipping networks. Because of this network configuration, large hubs are important at the global scale for global connectivity, while smaller ports 
are key for connectivity at the regional level (Ducruet and Zaidi, 2012). More recently, the use of multilayered networks suggested that nodes could have different positions and connectivity levels in a network according to different criteria or relationships linking them, each criterion represented as a layer in a multi-layer network (Bocaletti et al., 2014). In the case of Maritime Transportation, Kaluza et al. (2010) and Ducruet (2013) suggested that the global shipping network is a multi-layered structure of three classes of cargo ships that spanned distinct subnetworks, with different ports being critical for global connectivity in each layer. Ducruet (2013) also analysed the interdependencies at stage between the maritime transport network and different commodity flows, and found a very strong influence of commodity diversity on the distribution of maritime traffics among ports.

In addition to the metrics that assess connectivity based on the number of connections or links in the network and/or the number of connections available at a specific node in the network, other connectivity metrics have recently been developed to account for the quality of connections. These metrics assess the strength of the connection between two nodes in a network by looking, among other factors, at the capacity of the connection, the level of competition in a connection, or the feasibility of a connection (Burghouwt and Redondi, 2013). For example, Lam and Yap (2011) combined the number of vessels calling at a certain point with the capacity of such vessels in terms of TEUs. UNCTAD (2016) developed the Liner Shipping Connectivity Index (LSCI), which calculates a country's degree of connectivity based on four components: (i) number of containerships calling at the country's ports; (ii) container carrying capacity; (iii) number of shipping companies, liner services and vessels available in a country; and (iv) average and maximum vessel size. In addition, UNCTAD (2016) has just released the Liner Shipping Bilateral Connectivity Index, which estimates connectivity between pairs of countries and apply a threshold to assess the feasibility of a connection between countries according to a maximum number of transshipments allowed between them.

The estimation of connectivity based on the availability and characteristics of transport services relates to a narrow definition of connectivity present in the literature (Marquez-Ramos et al., 2011). In addition to this definition, a broader perspective is emerging. Aside from transport services, this perspective includes infrastructure and trade facilitation procedures as important elements to assess connectivity to international markets (Arvis and Shepherd, 2015). This broader perspective on connectivity is the one endorsed by the studies and programmes commissioned by policy-makers (ITF, 2012). Indeed, literature in International and Transport Economics has provided evidence that trade flows can be critically affected by not only transport services, but also by infrastructure and trade facilitation performance. For example, Clark et al. (2004) estimated that improving port efficiency from the $25^{\text {th }}$ to the $75^{\text {th }}$ percentile reduced maritime freight rates by $12 \%$ and raised bilateral trade by $25 \%$. Wilson et al. (2003) showed a high elasticity of trade flows to port efficiency (+4.2) and regulatory environment (-1.56). Nordas et al. (2006) estimated that a $10 \%$ delay in transport time due to inefficient trade facilitation procedures reduced the value of trade between 8 and 40\%. Hummels (2001) and Hummels and Schaur (2013) estimated that each additional day of transport was equivalent to imposing an ad valorem tariff of 0.6$2.3 \%$ and that it reduced the possibility of a country to export to the United States by between $1.0 \%$ and 1.5\%. Therefore, aside from better transport services, improvements in infrastructure and in trade 
facilitation procedures can help reduce cost and time to reach international markets, and increase trade flows (Djankov et al., 2010).

However, a metric of connectivity that takes into account transport, infrastructure and trade facilitation performance is still missing. In line with the broader perspective on connectivity increasingly embraced by policy-makers, this paper aims to provide an approach that, rooted in Graph Theory and Network Analysis, allows for a more comprehensive assessment of the variables that influence a country's degree of connectivity to international markets according to the broader definition of connectivity found in the literature - that is, infrastructure, transport services, and trade facilitation performance. A partial perception can misguide policy-makers and practitioners in their assessment of a country's degree of connectivity, the factors hindering it and the actions needed to overcome limitations. For example, a country could focus on improving the performance of its ports, but its connectivity to international markets could still be limited by the low availability of shipping services calling at them, or by trade facilitation procedures so cumbersome that could affect the efficiency of port operations.

In addition, the approach proposed in this paper allows for the specific assessment of a country's degree of connectivity to international markets. Despite increasing attention from both academia and policymakers, a measure of a country's degree of connectivity to its international markets is still lacking. Available research and metrics assess a country's connections in the context of transport networks only, but without taking into account whether and to what extent those connections matter for economic activities. Given that trade flows need transport services to reach their destination markets, and that transport costs impact on the extent of trade flows, it is critical that a country has a fast, smooth access to its international markets. Therefore, this paper aims to close the gap by proposing an approach that enables the assessment not only of the factors that influence a country's degree of connectivity according to a broader definition of connectivity, but also the extent to which those connections matter for its international economic activities.

\section{Methodology}

Network analysis was used to develop a new approach to assess a country's degree of connectivity to international markets. Using network analysis allowed for consideration of the different factors enabling connectivity to international markets through different network layers and attributes. The approach proposed entailed the design and analysis of the multi-layered network of international trade flows and its 'support network'.

Due to the predominance of containerisation and maritime transportation in international trade, as well as the availability of liner shipping data, the focus of this research was on containerised trade moved by containerships. Indeed, according to UNCTAD (2015) containerised cargo represents more than half the value of all international seaborne trade and around one sixth of its volume. One geographic region was selected for applying the approach proposed, the Americas (encompassing North, Central and South 
America, and the Caribbean), which includes 34 countries $^{1}$ and shows high intensity of intra-regional trade flows. Focusing the analysis on the Americas provides a further contribution to the literature. Indeed, while there is research on trade and transport networks at the global scale and other regional scales (Hu and Zhu, 2009; Mohamed-Cherif and Ducruet, 2016), an analysis focusing exclusively on the Americas is still missing. Furthermore, it was necessary to delimit the research to a defined region so as to allow for more in-depth and focused analysis. Given the purpose of this research was primarily to analyse the structure of the network that enables connectivity to international markets, and not the trends and evolution of the network, data was collected for one point in time only. Following a detailed analysis on data availability and validity, the year 2011 was selected for the analysis. Within the period 2007-2014 (the period for which data on trade facilitation was available), 2011 was selected as it was the most stable year in the Americas in terms of economic and weather factors, since there were neither trade shocks nor major natural disasters in the Americas in 2011 that affected trade and transport flows within the region.

The first step to analyse connectivity to international markets through network analysis was to build the containerised international trade network (ITN) in the Americas. This first step was important because connectivity is not an absolute measure. Countries in the Americas needed to connect to those countries they exported containerised products to. Therefore, it was crucial to understand the trade patterns among countries in the Americas first and then assess whether countries were connected to those markets, or whether there were barriers or opportunities lost due to the specific configuration of the SN. To build the ITN, COMTRADE data in US\$ value was used (Barigozzi et al., 2011). Since the focus of this paper is on maritime containerized trade, the researchers followed Wilson and Benson (2009) and Wilmsmeier et al. (2006) to identify in the COMTRADE database those commodities that had medium to high probability of containerisation. Out of the 99 commodities included in the COMTRADE database, 78 commodities were selected, representing $70 \%$ of the total value of intra-regional trade leaving aside fuel exports. In addition, to identify containerized trade transported by sea, the database was adjusted to reflect the modal split between country pairs. Modal splits for bilateral trade were estimated according to statistics from national and international agencies (ECLAC, 2010; IADB, 2012; USDOT, 2014).

Following De Benedictis and Tajoli (2011), the ITN consisted of:

$$
\operatorname{ITN}=(N, L, W)
$$

where $N=\{1,2, \ldots, n\}$ was the number of nodes, or the countries, in the ITN, and $L$ was a set of links between pairs of $N$. $L$ could have one or two directions, meaning that country $i$ could export to country $j$, or it could both export to and import from $j . W$ indicated the strength of the relationship between two countries. Following De Benedictis and Tajoli (2011), the degree $k_{i}$ of country $i$-or the total number of linkages to and from country $i-$ in year $t$ was given by the total exports from $i$ to $j\left(k_{i}^{\text {out }}\right)$ and the imports

\footnotetext{
${ }^{1}$ Argentina, Antigua and Barbuda, Bahamas, Belize, Bolivia, Brazil, Barbados, Canada, Chile, Colombia, Costa Rica, Dominica, Dominican Republic, Ecuador, Grenada, Guatemala, Guyana, Haiti, Honduras, Jamaica, St. Kitts and Nevis, St. Lucia, St. Vincent and the Grenadines, Mexico, Nicaragua, Panama, Peru, Paraguay, El Salvador, Suriname, Trinidad and Tobago, Uruguay, United States, Venezuela.
} 
from $j$ to $i\left(k_{i}^{i n}\right)$. The total degree $T$ of country $i\left(k_{\mathrm{i}}^{T}\right)$ in year $t$ was given by the sum of its in-degree and out-degree:

$$
k_{i}^{T}(t)=k_{i}^{\text {in }}(t)+k_{i}^{\text {out }}(t)
$$

The direct adjacency matrix $a_{i j, c}$ of trade flows among countries in the Americas was inputted into the software package Gephi ( Bastian et al., 2009) for network visualisation and analysis.

The 'support network' (SN) was built next. In line with the broader perspective on connectivity, the SN can be defined as the network of liner shipping services, port infrastructure, and trade facilitation procedures that enable connection to international markets. In order to build the SN, liner shipping services data was gathered from Containerization International (2012), data on port infrastructure quality was obtained from the Executive Opinion Survey conducted by the World Economic Forum (WEF, 2012), and trade facilitation data was gathered from the Doing Business database (World Bank, 2012). These data were inputted into Gephi to produce two networks: the Maritime Shipping Network or 'MSN' (the directed network of shipping services calling at ports in the Americas), and the SN (the MSN, port infrastructure quality and trade facilitation attributes). The MSN contained 2,028 links between country pairs. Variables on the availability and quality of maritime transport services were used to measure the strength of such links. For each country, data was gathered on containership deployment; container carrying capacity; and service frequency (Wilmsmeier et al., 2006; Ducruet and Notteboom, 2012). Links were weighted according to the following formula:

$$
W_{l}=\sum_{i=1}^{k} V_{i} Q_{i} F_{i}
$$

where $W_{1}$ was total weight of link $I, V_{i}$ was average vessel size deployed in service $i, Q_{i}$ was the number of vessels deployed in service $i$, and $F_{i}$ was the annual frequency with which service $i$ links two given countries. According to Lam and Yap (2011), despite the fact that detailed information on the actual load of each container and its precise origin and destination is not publicly available, this way of calculating links weight can reveal the connectivity between countries in a systematic and quantifiable manner. Indeed, extant literature suggests that due to the high correlation between container throughput and port hierarchies measured via vessel movements, this can be a reasonable proxy for actual links weight (Xu et al., 2015).

The SN consisted of:

$$
S N=(N, L, W, Y)
$$

where $N=\{1,2, \ldots, n\}$ was the number of nodes, or the countries, in the MSN; $L$ was determined by the existence of a maritime connection between two countries in the MSN; $W$ referred to link weight or the characteristics of maritime transport services deployed in that connection. Variables referring to the ease of accessing the network (infrastructure and trade facilitation performance) were contained in $\mathrm{Y}$, which referred to the characteristics of a given node. Gephi was used to design the SN, by modelling nodes' and links' characteristics to understand the performance of the SN. 
Port infrastructure quality was modelled as a node's attribute using a temperature scale. Data for this indicator was generated from the WEF Executive Opinion Survey 2011-2012, a business executives' perception survey that is conducted on a yearly basis. In the survey business executives in each country are asked the question: "How would you assess port facilities in your country?" Business executives ranked port facilities in a range of 1 to 7 , where $1=$ extremely underdeveloped; and $7=$ well-developed and efficient by international standards. Each country obtained a score between 1 and 7. Countries were ranked according to their scores, obtaining a scale from best to worst performer. The best performer among countries in the Americas in 2011 was Panama with a score of 6.4 points $=100 \%$. Results for the other countries were rescaled according to their distance to the best performer, and grouped into 6 ranges: $100 \%$; $80-99 \% ; 60-79 \% ; 40-59 \% ; 20-39 \%$; and 0-19\%. Using a temperature scale, each range received a colour (see Figure 7 below). Using Gephi, nodes' colours were modified according to the range that countries belonged to in the temperature scale.

Trade facilitation performance was also modelled as a node's attribute using a size scale. Data for this indicator was generated from the 'Trading across borders' indicator of the Doing Business report (World Bank, 2012). The 'Trading across borders' indicator measures time and costs associated with fulfilling official procedures for importing and exporting a 20-foot container by maritime transportation. Each country obtains a score between 0 (the lowest) and 100 (the highest). Countries in the Americas were ranked according to the scores they got in 2011, obtaining a scale from best to worst performer. The best performer in 2011 was also Panama with a score of 91.82 points $=100 \%$. Results for the other countries were rescaled according to their distance to the best performer. Using Gephi, nodes' sizes were modified according their distance to the best performer.

After building the ITN and the SN, network analysis and metrics were used to assess global and local connectivity. This included metrics such as in-degree; out-degree; total degree; alpha, beta and gamma indices; clustering coefficient; average path length (APL); diameter; and betweenness centrality (Wang et al., 2011) (Table 1). In order to identify whether and to which extent countries in the Americas were connected to their international markets, a multi-layered network encompassing trade patterns (ITN), and transport, infrastructure and trade facilitation factors (SN) was built and analysed (Table 2). 


\begin{tabular}{|l|l|l|}
\hline Metric & Definition & Formula \\
\hline Total in-degree & $\begin{array}{l}\text { The number of links a node receives from other } \\
\text { nodes }\end{array}$ & $k_{i}^{\text {in }}(t)=\sum_{j=1}^{N(t)} a_{i j}(t)$ \\
\hline Total out-degree & The number of links a node sends to other nodes. & $k_{i}^{\text {out }}(t)=\sum_{j=1}^{N(t)} a_{j i}(t)$ \\
\hline Total degree & The sum of in and out degrees & $k_{i}^{T}(t)=k_{i}^{\text {in }}(t)+k_{i}^{\text {out }}(t)$ \\
\hline Alpha index & $\begin{array}{l}\text { The ratio of actual to maximal number of circuits in } \\
\text { a fully connected network. }\end{array}$ & $\propto=\frac{2(e-n+1)}{(n-1)(n-2)}$ \\
\hline Beta index & The average number of links $(k)$ per node $(n)$ & $\beta=e / n$ \\
\hline Gamma index & The ratio of actual to maximal number of links $(k)$ & $\gamma=2 e /[n(n-1)]$ \\
\hline $\begin{array}{l}\text { Clustering } \\
\text { coefficient }\end{array}$ & $\begin{array}{l}\text { The portion of actual links }\left(L_{j}\right) \text { between the nodes } \\
\left(k_{j}\right) \text { within its neighbourhood divided by the } \\
\text { maximal possible edges }\left(k_{i}\left(k_{i}-1\right) / 2\right) \text { between them }\end{array}$ & $C_{i}=\frac{L_{i}}{k_{i}\left(k_{i}-1\right) / 2}$ \\
\hline APL & $\begin{array}{l}\text { The average number of links along the shortest } \\
\text { paths for all possible node-pairs in the network }\end{array}$ & $A P L=\frac{1}{\frac{1}{2} n(n-1)} \sum_{i>j} d_{i j}$ \\
\hline Betweenness \\
centrality
\end{tabular}

Table 1. Global and local connectivity metrics

\begin{tabular}{|l|l|}
\hline Network & Definition \\
\hline $\begin{array}{l}\text { International Trade } \\
\text { Network (ITN) }\end{array}$ & $\begin{array}{l}\text { The directed network of international trade flows between countries in } \\
\text { the Americas. }\end{array}$ \\
\hline $\begin{array}{l}\text { Maritime Shipping } \\
\text { Network (MSN) }\end{array}$ & $\begin{array}{l}\text { The directed network of shipping services calling at ports in the } \\
\text { Americas. }\end{array}$ \\
\hline Support Network (SN) & $\begin{array}{l}\text { The network of liner shipping services, port infrastructure, and trade } \\
\text { facilitation procedures that enable connection to international markets. }\end{array}$ \\
\hline
\end{tabular}

Table 2. Networks

\section{Results and discussion}

Figure 1 shows the ITN in the Americas. The analysis of the ITN using network metrics showed that, when taking into account the number of connections, the ITN in the Americas was overall moderately to highly connected: all countries were connected to at least $35 \%$ of the countries, while on average each country traded with 24.4 countries (average degree of the ITN). As a result, the density of the network and the clustering coefficients were high ( 0.65 and 0.74 respectively), while the APL and the diameter were, logically, very low (1.35 and 2 respectively). This means that, within the network, any country could reach any other country within two steps only, resulting in a strongly-connected network, with 
one strongly-connected component. These findings are in line with evidence provided by the literature that studied the global trade network, which suggested that the network was tightly connected at the regional level and that there was a strong propensity to trade with neighbouring countries (Barigozzi et al., 2011). Apart from proximity, intra-regional trade in the context of the Americas is explained by other factors such as common language, a certain degree of economic complementarity, strong historical ties, and the presence of a variety of trade and integration agreements between countries, including the North American Free Trade Agreement (NAFTA), the Central American Free Trade Agreement (CAFTA) and the Common Market of the Southern Cone (MERCOSUR).

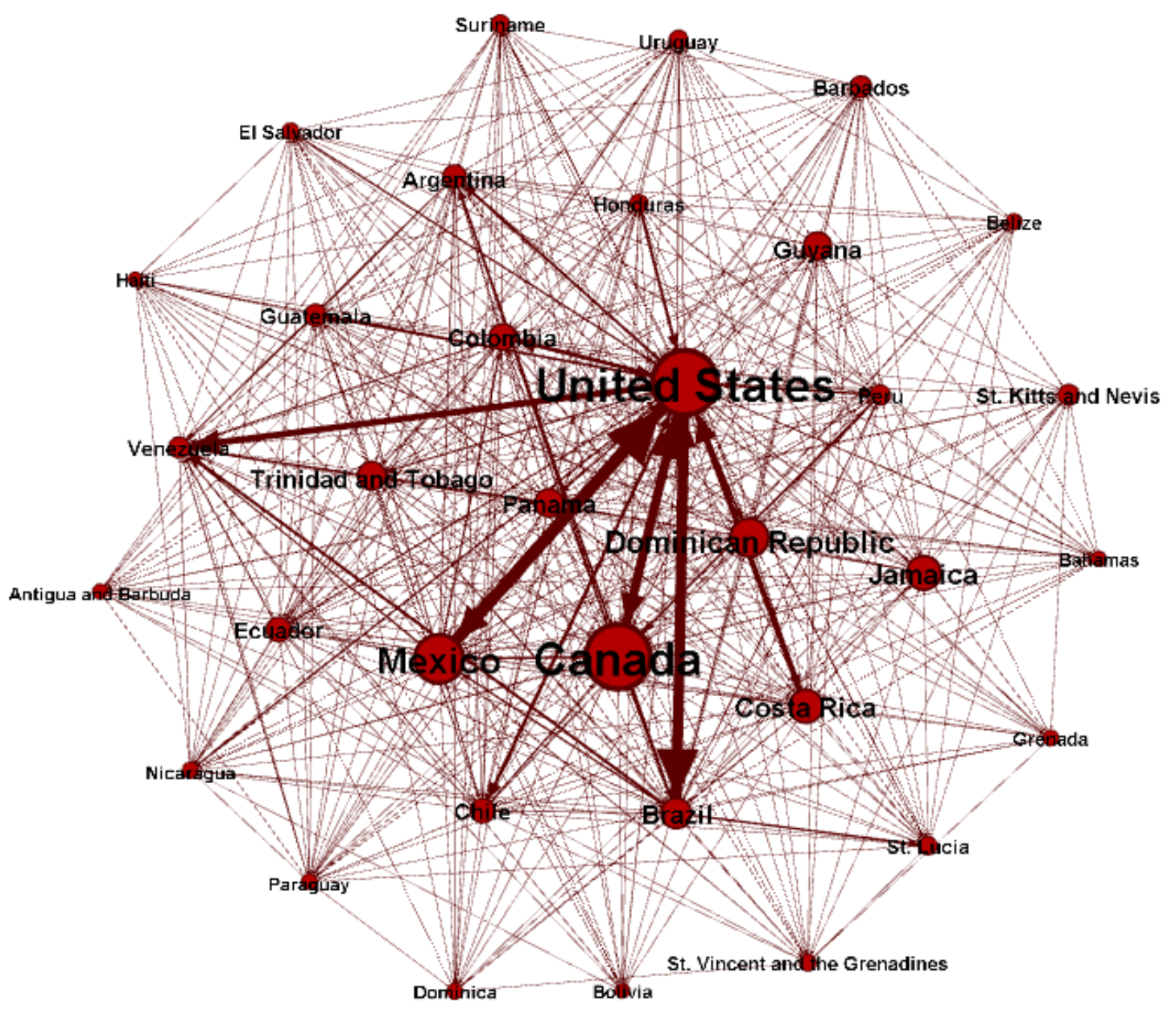

Figure 1. The ITN

Source: Authors based on COMTRADE data. The network was built using Gephi and displayed using the Fruchterman and Reingold algorithm. The size of the nodes varies according to countries' total degree. The size of the linkages varies according to the value of trade between countries. 
When taking into account links weight, or the value of trade between countries in the network, a very different network topology emerged. The top $20 \%$ of the countries (United States, Brazil, Mexico, Canada, Venezuela, Colombia, Argentina and Chile) concentrated $80 \%$ of the value traded within the ITN. In particular, one country (United States) accounted for $35 \%$ of total trade in the ITN. In contrast, the bottom $20 \%$ of the countries - mostly small islands in the Caribbean - accounted for only $0.5 \%$ of trade. The countries with higher GDP in the Americas had the highest links weight. In the specialized literature, this is called the 'size effect' of the nodes: "high-income countries tend to have more, and more intense, trade relations" (Fagiolo et al., 2009, p. 8). As a result, richer countries have higher degree centrality and tend to occupy a more central position, whereas the peripheral position is held by smaller, poorer countries (Fagiolo et al., 2009). In agreement with the available literature on the global trade network, the analysis of the ITN showed: (i) a small number of countries prevailing within the network; (ii) the coexistence of a few intense linkages with a majority of weak connections; and (iii) a 'rich club phenomenon', for which trade was concentrated among the countries with higher GDP (Duenas and Fagiolo, 2013). In addition to GDP, other factors can help explain the central position of certain countries in the ITN. Foreign direct investment, the presence of trade agreements such as NAFTA and CAFTA, economic complementarity, and historic and cultural ties, including intra-regional migration, make the USA the most important trade partner in the Americas for almost every country, and in particular Canada, Mexico and countries in Central America and the Caribbean. Likewise, the export-led policies adopted by Colombia and Chile, together with their bilateral trade agreements with the USA place both countries among the top exporters in the Americas and thus central in the ITN.

Figure 2 shows the MSN in the Americas. When comparing the topologies of the MSN and the ITN, the analysis showed that connectivity in the MSN was lower (Table 3). For example, in the MSN there were on average only 11.29 links per node (beta index), it required up to three hops to get to the most distant node in the network (diameter), node's neighbours were less connected (clustering coefficient), and the network only had $33 \%$ of all the links it could have had among all nodes (gamma index). The difference in connectivity levels between the two networks was explained by their different structures. In line with evidence from the literature that analysed the global maritime network (Hu and Zhu, 2009; Ducruet et al., 2010; Kaluza et al., 2010; Ducruet and Notteboom, 2012), the MSN presented a 'hub-and-spoke' structure and tested positive for a scale-free network with a power-law distribution of network links, meaning that a reduced number of countries had a large number of connections and that connectivity opportunities were unequally distributed among nodes (Figures 3 and 4) (Gonzalez-Laxe et al., 2012). In contrast, the ITN was a small-world network, where nodes were tightly connected in a 'point-to-point' network configuration. Because of this structure, the MSN did not entirely overlap trade patterns, resulting in some countries with fewer connections having more difficulty in reaching their international markets. Therefore, the 'hub-and-spoke' configuration of the MSN, determined by the strategies of shipping lines, had an important role in a country's higher or lower degree of connectivity to its international markets. Statistical analysis also showed a different degree of connectivity for nodes in when comparing the ITN and the MSN. Results suggested a moderate correlation between nodes' degrees in the ITN and the MSN (0.68), meaning that nodes in the MSN-all were not as densely connected as they were in the ITN. Statistical analysis also showed a moderate correlation between nodes' rankings $(0.72)$, meaning that countries did not always have the same level of importance in both 
networks. Looking closer at the data, this can be explained, for example, by the lower connectivity of important trade players such as Canada and Uruguay in the MSN and, conversely, the higher connectivity in the MSN of less important trade players such as Grenada and Haiti.

These findings on the different structure of the ITN and the MSN are in line with the literature in Transport Geography that questions the conventional perspective in Transport Economics, which suggests that transportation is a derived demand from economic activities (Rodrigue, 2006). According to this perspective, freight movements are the direct outcome of the supply and demand of raw materials, parts and final products by firms or individuals located in different countries. Without trade demand being located in another country, demand for international freight transport would simply not take place (Bamford, 2001). However, freight distribution encompasses complex transport systems (Hesse and Rodrigue, 2006). The organization of such transport systems responds to a variety of factors aside of the specific characteristics of trade. As evidenced by the different structure of the ITN and the MSN, this leads to transport systems not always matching the structure of trade flows.

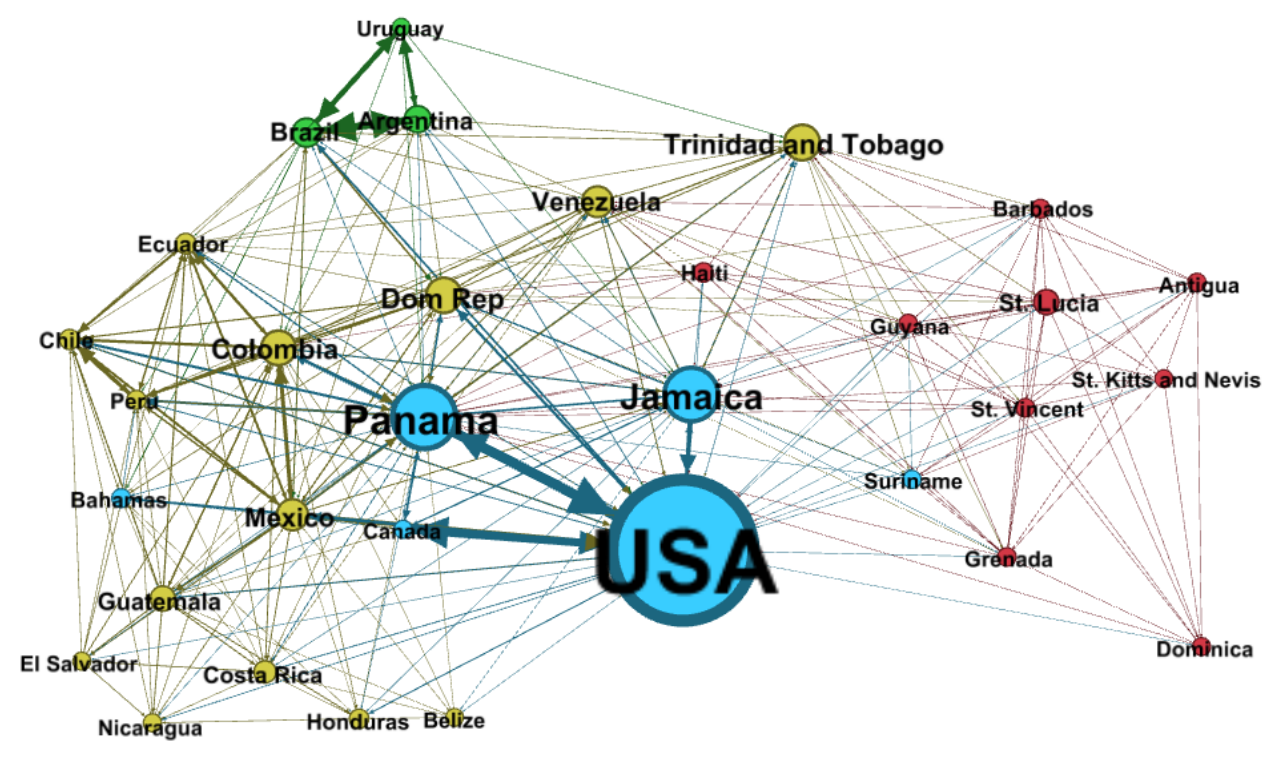

Figure 2. MSN

Source: Authors. MSN displayed using Gephi. Node's size according to betweenness centrality. Node's colour according to maritime community. Links weight according to capacity of shipping connection between countries (total TEUs in 2011). 


\begin{tabular}{|l|l|l|}
\hline Metrics & MSN & ITN \\
\hline Alpha index & 0.661 & 1.276 \\
\hline Beta index & 11.29 & 27.235 \\
\hline Gamma index & 0.33 & 0.825 \\
\hline Diameter & 3 & 2 \\
\hline APL & 1.626 & 1.175 \\
\hline $\begin{array}{l}\text { Clustering } \\
\text { coefficient }\end{array}$ & 0.639 & 0.845 \\
\hline
\end{tabular}

Table 3. Global connectivity in the MSN and the ITN

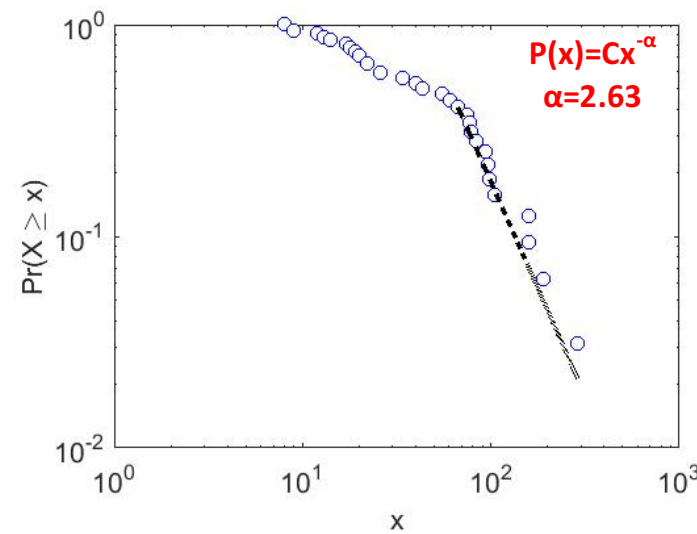

Figure 3. MSN - testing for power-law distribution

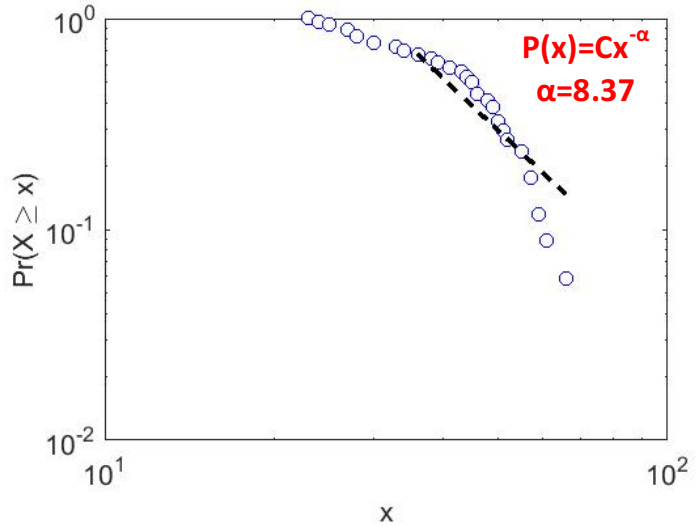

Figure 4. ITN - testing for powerlaw distribution

In agreement with the literature that studied the global and other regional shipping networks (Ducruet et al., 2012; Mohamed-Cherif et Ducruet, 2015; Xu et al., 2015), the analysis of the origin and destination of links in the MSN showed that countries were mainly connected to their geographic neighbours and regional/global hubs and, to a lesser extent and intensity, to some of their main trade partners. Indeed, only $41 \%$ of number of ITN links had a direct - without transhipment - MSN connection (Figure 7). Due to the 'hub-and-spoke' structure of the MSN, a country's exports often had to go through third countries before getting to destination. These third countries were neighbours in a given MSN community, regional connectors and global hubs. Four communities emerged in the MSN: (i) a community gathering two North American countries (USA and Canada) with countries that acted as hemispheric hubs in the MSN (Panama and Jamaica); (ii) a community gathering countries in the Southern Cone with shores on the Atlantic coast (Brazil, Argentina and Uruguay); (iii) a community gathering Caribbean countries; and (iv) a community gathering countries in Central America and the West Coast of South America (WCSA) (Figure 2). Communities were identified by applying the 'Louvain method' for community detection in Gephi (Blondel et al., 2008). In the MSN, countries were more 
tightly connected to other countries that belonged to the same community. Among community neighbours, certain countries played a more critical role for connectivity to international markets since they acted as connectors between communities, thus allowing countries in the different communities to be connected not only to their neighbours, but also to countries in other communities. This was revealed by their higher betweenness centrality. For example, Brazil emerged as a critical connector between the Southern Cone community and the rest of the network. Likewise, Trinidad and Tobago acted as the bridge between the Caribbean community and the other communities in the MSN, and Colombia played the regional hub role for WCSA. In turn, US, Panama and Jamaica acted as global hubs in the MSN. Their presence was critical for global connectivity since they connected to different communities, to global and regional hubs, and to individual countries, enabling connection among all the nodes they were connected to. Due to the 'hub-and-spoke' structure of the MSN, the position of global and regional hubs provided an advantage for these countries in terms of connecting to international markets. Indeed, their exports could reach their destination markets with fewer steps and transhipments than countries with a less central position.

To further analyse to what extent countries were connected to their trade partners in the MSN - their international markets - connectivity at the local level was analysed. A sample of countries was selected for the analysis of connectivity patterns from a nodes' (or a country's) perspective. The selection was stratified, in order to have representation from highest, middle and lowest traders in 2011. Countries were ranked from 1 to 34 according to their trade value in 2011. Based on this ranking, six countries were selected for the analysis: top two traders (USA and Mexico); middle two traders (El Salvador and Venezuela); and bottom two traders (Antigua and Dominica). For each of these six countries, their main three trade partners where considered, for a total of 18 partnerships. The results from the analysis (Table 4) showed that only 17\% (3) of the ITN partnerships analysed were supported by direct linkages in the MSN. These partnerships were: Mexico-US, Mexico-Colombia, and Venezuela-US. While in most of the cases countries were not connected to their trade partners in the MSN, the analysis of the top three MSN connections for each country (based on higher percentage of TEUs deployed in the connection) showed that they were densely connected to global/regional hubs and neighbouring countries instead. For example, in the case of Brazil, it had a direct connection with one of its main trade partners (Argentina), but in the MSN it was mainly connected to a geographical neighbour (Uruguay) and a global network hub (DR) which allowed Brazil to reach countries in the different network communities. In the case of El Salvador, its main connections were to two community neighbours (Costa Rica and Ecuador) and the regional hub (Colombia). 


\begin{tabular}{|c|c|c|c|c|c|}
\hline Country & Partner & $\begin{array}{l}\text { ITN main } \\
\text { partner } \\
\text { (total US\$) }\end{array}$ & $\begin{array}{c}\text { Trade with } \\
\text { partner over } \\
\text { country's total } \\
\text { trade (\%) }\end{array}$ & $\begin{array}{l}\text { MSN main } \\
\text { partner } \\
\text { (total TEUs) }\end{array}$ & $\begin{array}{c}\text { Connection capacity } \\
\text { to partner over } \\
\text { country's total } \\
\text { capacity }(\%)\end{array}$ \\
\hline \multirow{3}{*}{ USA } & 1 & Brazil & $5.08 \%$ & Canada & $23.14 \%$ \\
\hline & 2 & Mexico & $6.89 \%$ & Panama & $20.80 \%$ \\
\hline & 3 & Venezuela & $2.05 \%$ & Dom Rep & $7.19 \%$ \\
\hline \multirow{3}{*}{ Mexico } & 1 & USA & $18.08 \%$ & USA & $18.81 \%$ \\
\hline & 2 & Canada & $1.12 \%$ & Colombia & $15.30 \%$ \\
\hline & 3 & Colombia & $15.29 \%$ & Panama & $8.98 \%$ \\
\hline \multirow{3}{*}{ El Salvador } & 1 & USA & $3.48 \%$ & Colombia & $22.27 \%$ \\
\hline & 2 & Canada & $0.00 \%$ & Costa Rica & $17.91 \%$ \\
\hline & 3 & Dom Rep & $0.00 \%$ & Ecuador & $13.43 \%$ \\
\hline \multirow{3}{*}{ Venezuela } & 1 & USA & $14.72 \%$ & $\begin{array}{l}\text { Trinidad } \\
\text { and Tobago }\end{array}$ & $17.36 \%$ \\
\hline & 2 & Brazil & $8.63 \%$ & USA & $14.72 \%$ \\
\hline & 3 & Mexico & $2.41 \%$ & Panama & $11.85 \%$ \\
\hline \multirow{3}{*}{ Antigua } & 1 & USA & $7.68 \%$ & Barbados & $18.06 \%$ \\
\hline & 2 & Mexico & $0.00 \%$ & St. Vincent & $14.20 \%$ \\
\hline & 3 & Canada & $0.00 \%$ & St. Lucia & $12.73 \%$ \\
\hline \multirow{3}{*}{ Dominica } & 1 & USA & $13.13 \%$ & St. Lucia & $28.70 \%$ \\
\hline & 2 & Dom Rep & $0.00 \%$ & Panama & $13.94 \%$ \\
\hline & 3 & Guyana & $0.00 \%$ & St. Vincent & $13.74 \%$ \\
\hline
\end{tabular}

Table 4. Top three ITN and MSN partners for selected countries (weight)

In summary, the analysis of connectivity at both global and local levels showed that countries were not always connected to their ITN partners. In addition, such connections not always had the same importance for the ITN and for the MSN. Indeed, Pearson's correlation between ITN and MSN was very low (0.38) for links weight and moderate (0.55) for links ranking (Figure 5). While in the ITN the most important links connected trade partners (for example, USA-Canada, USA-Mexico, Canada-USA), in the MSN the most important links connected either global and regional hubs or community neighbours (for example, Panama-USA, USA-Jamaica, Brazil-Argentina). This is in line with the results from studies on multi-layered networks, which show that relationship between nodes may change depending on the criteria under consideration (Bocaletti et al., 2014). 


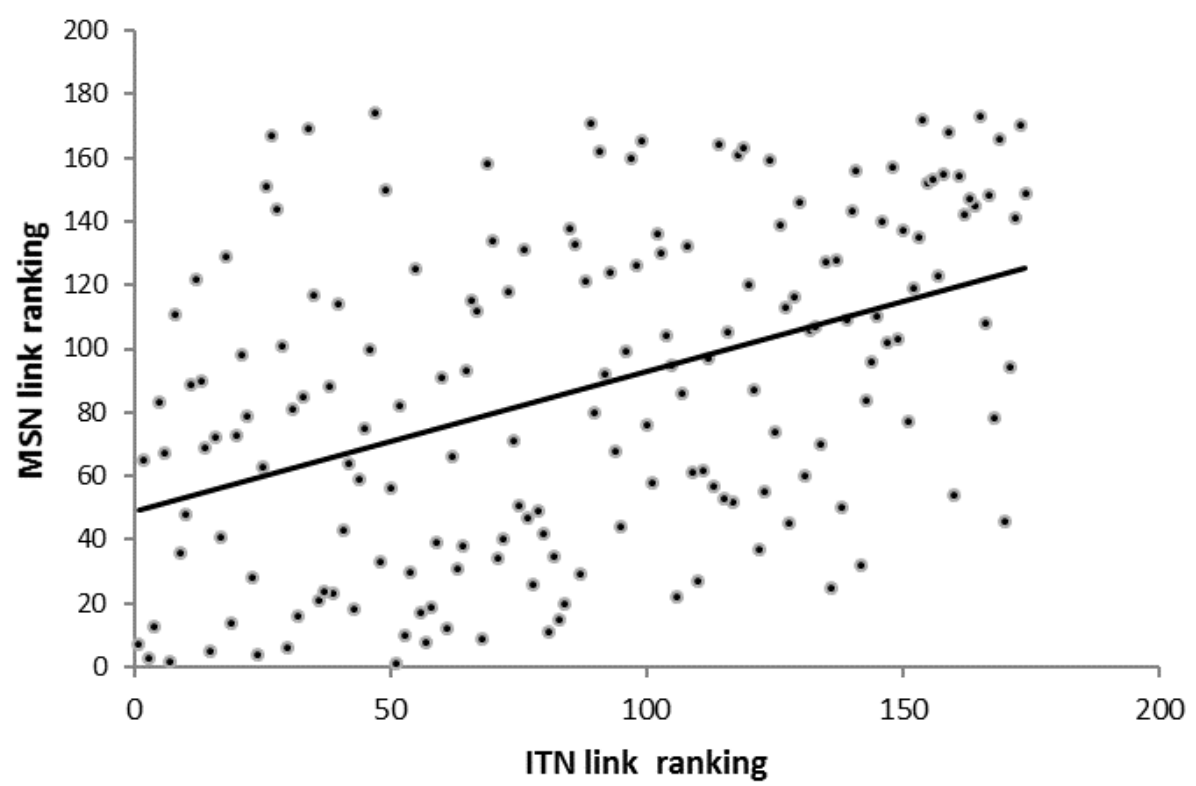

Figure 5. Correlation between links rankings in the ITN and MSN

Due to the MSN structure, a country's exports usually had to go through third countries before arriving at their destination markets (Lam and Yap, 2011). Therefore, a country's connectivity to international markets also depended on those third countries. This dependency is graphically illustrated in Figure 6, which visually represents the main 20 shipping routes in the Americas (making up to $80 \%$ of total MSN capacity available in 2011) as a metro-like map so as to grasp the particular characteristics of the MSN geographic structure. From the figure it can be noticed that in the case of Chile, for example, its connectivity depended also on Peruvian, Ecuadorian and Colombian ports, since the maritime services calling at Chilean ports - and transporting its exports to destination markets - also stopped at Chile's neighbours in the WCSA community (Peru and Ecuador) and the regional hub (Colombia). Likewise, given that all of the maritime services that connected Uruguay with its international markets also called at ports in Brazil and Argentina, the quality of port infrastructure in those countries and their level of connectivity were critical to Uruguay's connectivity. 


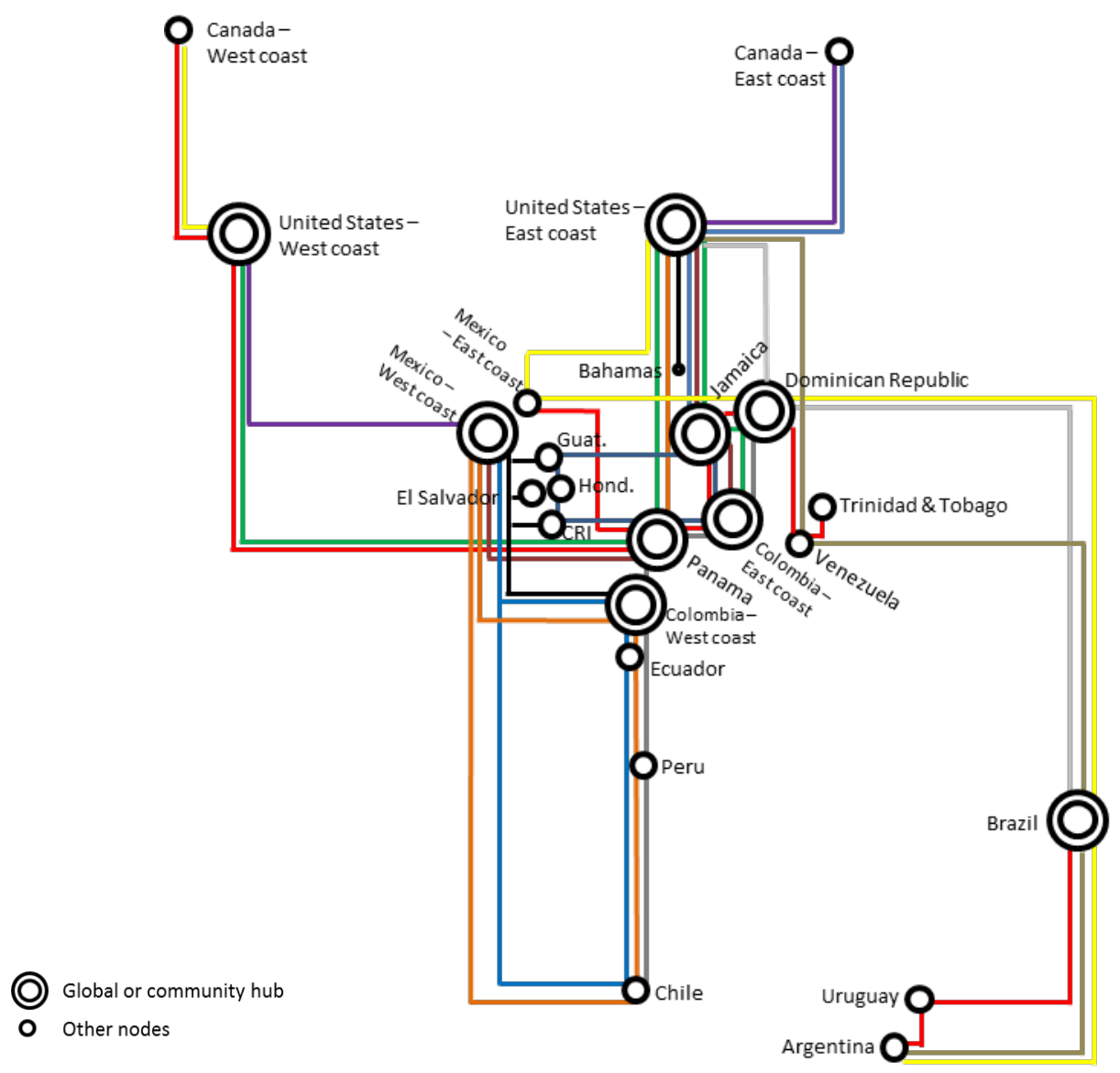

Figure 56. Metro-like organisation of the MSN*

* "West" and "East" shores were indicated for countries with shores on both Pacific and Atlantic oceans. For visual simplicity, Guatemala and Costa Rica were indicated with one node each.

Having analysed connectivity based on the characteristics of transport services - the narrow connectivity perspective - port infrastructure and trade facilitation components were included to account for the broader connectivity perspective found in recent academic and policy literature (Marquez-Ramos et al. 2011; ITF, 2012; xxx, 2016). More specifically, three categories of variables were used for the analysis of each country's degree of connectivity, each of these categories being in line with each component of the broader approach to connectivity to international markets. As explained in section 4, WEF port infrastructure quality variable was used to assess the port infrastructure component of connectivity, while the 'Trading across borders' indicator of the Doing Business report was used to assess the performance of trade facilitation procedures. To assess transport services, three metrics of local connectivity (Table 1) were used: node degree, node weighted degree, and betwenness centrality. Figure 7 is a visual representation of the each country's degree of connectivity based on these variables. 
The results from analysis of the SN provided more insights on country connectivity and dependency from third countries. When considering port infrastructure quality, the analysis showed that while some of the most important countries in terms of their total weighted degree had a good port infrastructure quality (Panama, USA and Jamaica) -many of the countries that acted as hubs and community connectors had a deficient infrastructure quality (Figure 7). This was statistically confirmed by the low Pearson's correlation (0.32) obtained between the position that countries occupied in the MSN as a function of their number of connections and their performance in terms of port infrastructure quality.

This was the case with Colombia, Brazil and Mexico, which acted as critical connectors between the global network and the WCSA community, the Southern Cone community and the Central America community, respectively, and thus had a high number of connections in the MSN, but occupied lower positions in the ranking of port infrastructure quality (position 19 for Brazil, 16 for Colombia and 10 for Mexico). In addition, when looking at the efficiency of port infrastructure and transport services at the community level, weakest links could be clearly evidenced. Given the tight connection among countries within the community, such inefficient infrastructure quality could negatively influence the connectivity of the entire community (Figure 7). For example, the bad infrastructure quality of Brazilian ports could negatively influence the connectivity of other countries tightly connected to them such as Uruguay and Argentina. The low infrastructure quality of Colombia and Peru could negatively influence the connectivity of Chile and Ecuador. Finally, the bad infrastructure quality of Nicaragua and Costa Rica could impact the connectivity of other countries in their community such as Guatemala and Honduras.

In addition to limited transport services and low port infrastructure quality, the efficiency of trade facilitation processes affected connectivity in the Americas. The best performers in this component were countries in the Caribbean, whose participation in the ITN was peripheral. This is in agreement with the very low correlation (0.24) obtained between countries' positions in the ranking of best trade facilitation performers and the ranking of countries' connections in the ITN. Many of the most critical links in the ITN had at least one country with medium-to-low performance in trade facilitation. This was the case of, for example in the following bilateral trades, US-Colombia, US-Brazil, US-Venezuela, US-Chile and Brazil-Argentina. 


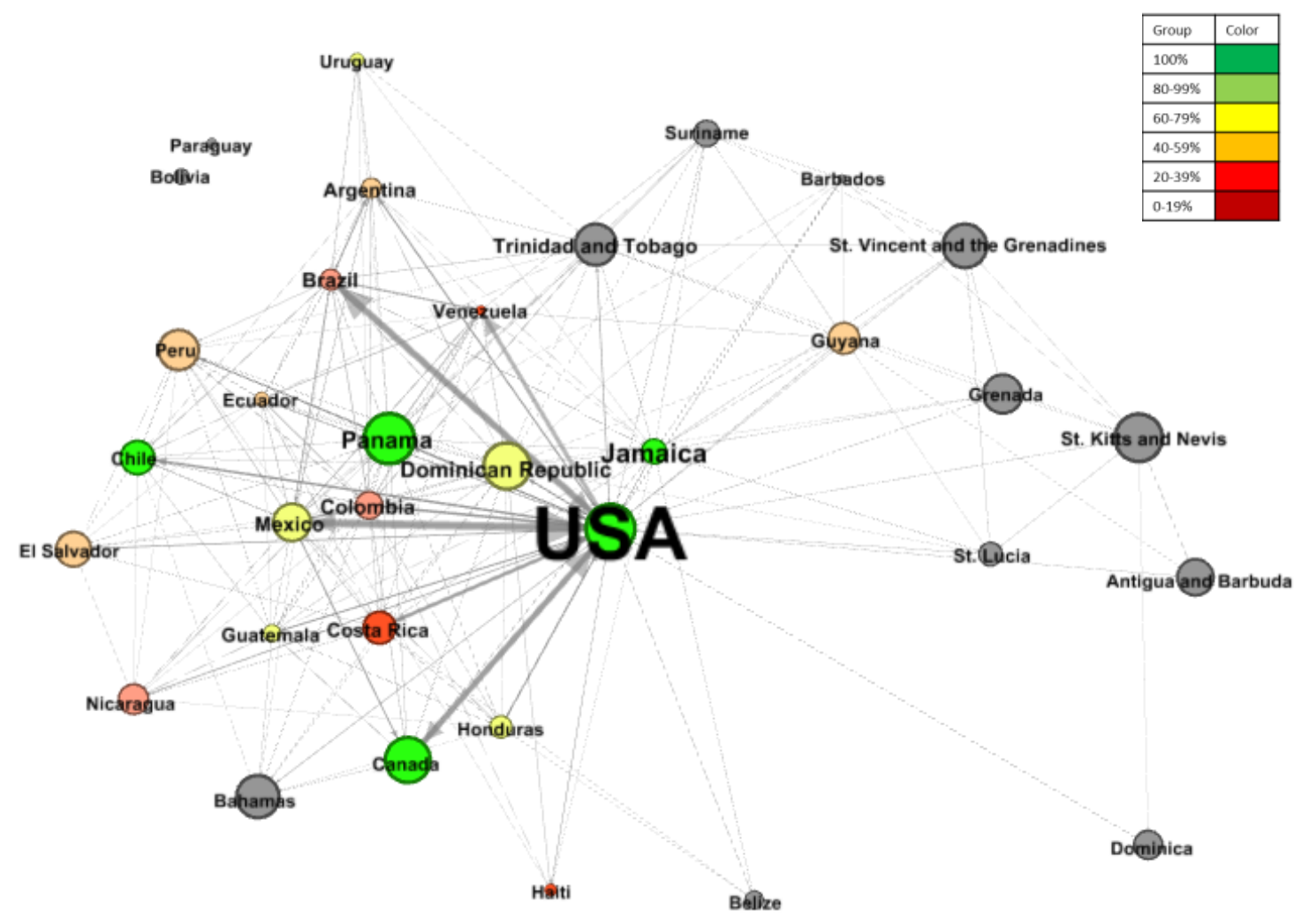

Figure 7. SN performance in the context of the ITN*

*ITN and SN were overlapped using Gephi. Nodes' colour: port infrastructure quality (distance from best performer). Nodes' size: DB (TAC) performance (distance). Edges weighted according to trade weight. Labels sized according to betweenness degree.

The results of this research can be useful for policy-making. Compared to the available connectivity metrics that focus on transport connectivity only (Marquez-Ramos et al., 2011), the approach proposed allows a more comprehensive understanding of a country's degree of connectivity to its international markets. This approach is in line with the broader connectivity perspective increasingly embraced by policy-makers and academia which, aside from transport services, includes infrastructure and trade facilitation procedures as important elements to assess connectivity to international markets (ITF, 2012; Arvis and Shepherd, 2015; xxx, 2016). The results from the approach proposed suggest that, in order to understand a country's degree of connectivity to international markets it is critical to understand how a country is positioned within the SN; its level of dependency from certain countries and shipping lines structures to reach its international markets; port infrastructure quality at origin, intermediate/transhipment and destination countries; and trade facilitation processes at origin and destination countries. In addition, a set of connectivity metrics has to be applied in order to comprehensively understand connectivity performance from both local and global perspectives. With particular reference to policy-making, the results from the use of this approach suggest, for example, that a country's transport and trade strategies cannot be designed without taking into account the trade and transport contexts (or networks) the country is embedded in. Indeed, such strategies need to 
acknowledge the level of dependency from other actors - both other countries and maritime shipping lines - and be able to minimise as much as possible the risks that emanate from this discrepancy. It also suggests that cooperation among countries is important to increase the resilience of the SN that allows trade flows to reach their destination countries. Therefore, aside from national port, transport or trade strategies, regional strategies could help increase connectivity. Although governments can only moderately influence the strategies of shipping companies, they can provide the required infrastructure and the legal framework under which these companies operate. In this context, and given the interdependency of countries in the MSN, regional strategies can be useful as a means to coordinate investment efforts with the goal to increase port performance at both the country and regional levels. In addition, governments can design a regional maritime legal framework aimed at streamlining administrative procedures and facilitating port operations. Finally, governments can collaborate at bilateral and multilateral levels in order to implement reforms focused on streamlining trade facilitation procedures. From the private sector perspective, this more comprehensive assessment of connectivity can inform facility location, sourcing and supply chain risk management strategies. Moreover, it can support private-public dialogue and partnerships for reaching existing and new international markets.

\section{Conclusion}

The results of this research advance knowledge in a topic that is of increasing relevance in the present context. The application of the approach proposed showed that, in the Americas, countries were seldom connected through maritime services directly to their international markets. The reason behind this is the different organisations of the ITN and the MSN. While the ITN is a 'point-to-point' structure, the MSN shows a 'hub-and-spoke' organisation, leading to the MSN not always matching the structure of trade flows. These findings are in line with the literature in Transport Geography that questions the conventional perspective in Transport Economics, which suggests that transportation is a derived demand from economic activities (Rodrigue, 2006). Indeed, the organisation of transport systems responds to a variety of factors aside of the specific characteristics of trade. In the case of maritime transportation, it depends on the strategies of liner shipping companies. In the Americas, results showed that only $41 \%$ of the ITN links had a direct MSN connection. Among the 18 trade partnerships analysed in the sample, only three were directly connected via shipping services. In general, connectivity in the MSN was lower than in the ITN, with just 11.29 links per node and only $33 \%$ of all the links that the MSN could have had. In addition, when trade partners were connected, the 'hub-and-spoke' structure of shipping lines made exports go on longer voyages before arriving to their market destinations as services were making multiple enroute calls. These calls included countries in the same maritime community, regional hubs and global hubs in the MSN. The MSN configuration increased dependency from such countries.

Aside from transport characteristics, the approach to measure connectivity to international markets suggested in this paper includes infrastructure and trade facilitation procedures. This is in line with the broader definition of connectivity available in the literature. Specifically, this paper suggests that to fully understand a country's degree of connectivity to international markets it is critical to understand how a 
country is positioned within the MSN; its level of dependency from certain countries and shipping lines structures to reach its international markets; port infrastructure quality at origin, intermediate/transhipment and destination countries; and trade facilitation processes at origin and destination countries. Importantly, connectivity has to be assessed in a relative fashion, taking into account where countries should be connected to and which are the countries that matter. This broader approach to measure connectivity can contribute to identifying and designing more effective policies to address barriers impeding the fast, smooth access to international markets.

Further research based on the results of this paper could focus on econometrically testing the relationship between the ITN and the SN, as well as analysing the issue of homophily in the networks to understand, for example, whether countries sharing similar characteristics are better connected than nodes without similar characteristics. Further research on connectivity to international markets could focus on collecting data for a broader period of time in order to analyse any variation over time in connectivity to international markets. In addition, further work could apply the proposed approach to other regions or country groups. This would enable comparison of connectivity levels among different regions or country groups, as well as provision of input for policy making to a broader group of countries. Finally, further research could expand the analysis to other transport modes as a means to assess a country's overall level of connectivity to its international markets.

\section{References}

APEC (2010) The Economic Impact of Enhanced Multimodal Connectivity in the APEC Region, Policy Support Unit. Singapore: APEC.

Arvis, J. and Shepherd, B. (2015) 'Measuring Connectivity in a Globally Networked Industry: The Case of Air Transport', The World Economy, 39(3), pp. 369-385.

ASEAN (2010) Master Plan on ASEAN Connectivity. Jakarta: ASEAN.

Barigozzi, M., Fagiolo, G. and Mangioni, G. (2011a) 'Community Structure in the Multi-network of International Trade', Complex Networks, 116, pp. 163-175.

Bastian, M., Heymann, S. and Jacomy M. (2009) 'Gephi: An Open Source Software for Exploring and Manipulating Networks', paper presented at the $3^{\text {rd }}$ National AAAl Conference on Weblogs and Social Media, San Jose, CA.

Bernhofen, D., El-Sahli, Z. and Kneller, R. (2016), 'Estimating the effects of the container revolution on world trade', Journal of International Economics, 98, pp. 36-50.

Blondel, V., Guillaume, J., Lambiotte, R. and Lefebvre, E. (2008) 'Fast unfolding of communities in large networks', Journal of Statistical Mechanics: Theory and Experiment, 2008(10), P10008 (12pp).

Boccaletti, S., Bianconi, G., Criado, R., del Genio, C., Gomez-Gardeñes, J., Romance, M., Sendiña-Nadal, I., Wang, Z. and Zanin, M. (2014) 'The structure and dynamics of multilayer networks', Physics Reports, 544(1), pp. 1-122.

Burghouwt, G. and Redondi, R. (2013) 'Connectivity in air transport networks an assessment of models and applications', Journal of Transport Economics and Policy, 47(1), pp. 35-53. 
Clark, X.M., Dollar, D. and Micco, A. (2004) 'Port efficiency, maritime transport costs, and bilateral trade', Journal of Development Economics, 75(2), pp. 417-450.

Containerization International (2012) Yearbook 2011. London: Informa Cargo.

De Benedictis, L. and Tajoli, L. (2011) 'The World Trade Network', World Economy, 34(8), pp. 1417-1454.

Djankov, S., Freund, C. and Pham, C.S. (2010) 'Trading on Time', Review of Economics and Statistics, 92(1), pp. 166-173.

Ducruet, C. (2013) 'Network diversity and maritime flows', Journal of Transport Geography, 30, pp.7788.

Ducruet, C. and Notteboom, T. (2012) 'The worldwide maritime network of container shipping: Spatial structure and regional dynamics', Global Networks, 12(3), pp. 395-423.

Ducruet, C., Rozenblat, C. and Zaidi, F. (2010) 'Ports in multi-level maritime networks: evidence from the Atlantic (1996-2006)', Journal of Transport Geography, 18(4), pp. 508-518.

Ducruet, C. and Zaidi, F. (2012) 'Maritime constellations: a complex network approach to shipping and ports', Maritime Policy and Management, 39(2), pp. 151-168.

Duenas, M. and Fagiolo, G. (2013) 'Modeling the International-Trade Network: a gravity approach', Journal of Economic Interaction and Coordination, 8(1), pp. 155-178.

ECLAC (2010) Latin American Modal Split in International Transport. Available from:

$<$ http://www.cepal.org/cgi-

bin/getProd.asp?xml=/Transporte/noticias/noticias/2/48132/P48132.xml\&xsl=/Transporte/tpl/p1f.xsl\& base=/transporte/tpl/top-bottom.xslt>. [3 March 2014].

Fagiolo, G., Reyes, J. and Schiavo, S. (2009) 'Dynamics and Evolution of the International Trade Network', Complex Networks, 207, pp. 1-13.

Gaile, G. and Willmott, C. (2004) Geography in America at the Dawn of the $21^{\text {st }}$ Century, New York: Oxford University Press.

Garrison, W. L. (1960) 'Connectivity of the Interstate Highway System', Papers of the Regional Science Association, 6, pp. 121-38.

Gonzalez-Laxe, F., Seoane, M.J.F. and Pais, C. (2012) 'Maritime degree, centrality and vulnerability: port hierarchies and emerging areas in containerized transport (2008-2010)', Journal of Transport Geography, 24, pp. 33-44.

Guerrero, D., Grasland, C. and Ducruet, C. (2016) 'Explaining international trade flows with shipping distances'. In Maritime networks: spatial structures and time dynamics, ed. C. Ducruet, Routledge, New York, NY.

Hesse, M. and Rodrigue, J.P. (2006) 'Global Production Networks and the Role of Logistics and Transportation', Growth and Change, 37(4), pp. 499-509.

Hu, Y.H. and Zhu, D.L. (2009) 'Empirical analysis of the worldwide maritime transportation network', Physica a-Statistical Mechanics and Its Applications, 388(10), pp. 2061-2071.

Hummels, D. (2001) Time as a trade barrier (GTAP Working Papers 1152). Indiana: Center for Global Trade Analysis, Purdue University. 
Hummels, D. and Schaur, G. (2013) 'Time as a trade barrier', American Economic Review, 103, pp. 29352959.

IADB (2012). Analysis, Strategies and Tools for Improving Freight Logistics and Trade Facilitation in Mesoamerica. Mimeo, Washington D.C.

ITF (International Transport Forum) (2012), Seamless Transport: Making Connections. Available from http://www.internationaltransportforum.org/2012/pdf/2012_Summit_Session\%20Summaries.pdf>. [20 November 2013].

Jacks, D. and Pendakur, K. (2010) 'Global Trade and the Maritime Transport Revolution', The Review of Economics and Statistics, 92(4), pp. 745-755.

Kaluza, P., Kolzsch, A., Gastner, M.T. and Blasius, B. (2010) 'The complex network of global cargo ship movements', Journal of the Royal Society Interface, 7(48), pp. 1093-1103.

Lam, J.S.L. and Yap, W.Y. (2011) 'Dynamics of liner shipping network and port connectivity in supply chain systems: analysis on East Asia', Journal of Transport Geography, 19(6), pp. 1272-1281.

Marquez-Ramos, L., Martinez-Zarzoso, I., Perez-Garcia, E. and Wilmsmeier, G. (2011) 'Special Issue on Latin-American Research Maritime Networks, Services Structure and Maritime Trade', Networks \& Spatial Economics, 11(3), pp. 555-576.

Mishra, S., Welch, T. and Jha, M. (2012) 'Performance indicators for public transit connectivity in multimodal transportation networks', Transportation Research Part A, 46, pp. 1066-1085.

Mohamed-Cherif, F. and Ducruet, C. (2015) 'Regional integration and maritime connectivity across the Maghreb seaport system', Journal of Transport Geography, 51, pp. 280-293.

Newman, M. (2003) 'The structure and function of complex networks', SIAM Review, 45, pp. 167-256.

Nordas, H., Pinali, E. and Geloso, M. (2006) 'Logistics and Time as a Trade Barrier', OECD Trade Policy Working Papers, N. 35, Paris: OECE Publishing.

Paleari, S., Redondi, R. and Malighetti, P. (2010) 'A comparative study of airport connectivity in China, Europe and US: Which network provides the best service to passengers?', Transportation Research Part E-Logistics and Transportation Review, 46(2), pp. 198-210.

Redondi, R., Malighetti, P. and Paleari, S. (2013) 'The accessibility of European regions and airport network', Transportation Research Part $E$, in press. Available from:

http://www.researchgate.net/profile/Renato_Redondi/publication/241753391_The_accessibility_of_Eu ropean_regions_and_airport_network/links/00b7d52579abc1554b000000.pdf

Rodrigue, J.P. (2006) 'Challenging the derived transport-demand thesis: geographical issues in freight distribution', Environment and Planning A, 38, pp. 1449-1462.

Salgado, O. and Cea, P. (2012) 'External connectivity analysis on the ports of Chile as a factor of competitiveness', Ingeniare. Revista chilena de ingenieria, 20, pp. 25-39.

Salvatore, D. (2002) International Economics. Milan: John Wiley \& Sons.

Sheppard, E. (2000) 'Geography or Economics? Conceptions of Space, Time, Interdependence, and Agency'. In A Handbook of Economic Geography, eds. G. Clark, M. Gertler, and M. A. Feldman, Oxford University Press, Oxford, 99-124.

Thill, J.C. (2000) Geographic Information Systems in Transportation Research. London: Pergamon Press. UNCTAD (2013 and 2015) Review of Maritime Transport, Geneva: UNCTAD. 
UNCTAD (2016) Liner Shipping Connectivity Index and Liner Shipping Bilateral Connectivity Index. Available from: <http://unctadstat.unctad.org/TableViewer/tableView.aspx?Reportld=92>. [1 May 2016].

USDOT (2012) Freight Facts and Figures 2011. Available from:

<http://ops.fhwa.dot.gov/freight/freight_analysis/nat_freight_stats/docs/12factsfigures/index.htm>. [1 March 2014].

Wang, J.E., Mo, H.H., Wang, F.H. and Jin, F.J. (2011) 'Exploring the network structure and nodal centrality of China's air transport network: A complex network approach', Journal of Transport Geography, 19(4), pp. 712-721.

WEF (2012) Global Enabling Trade Report 2012. Available from:

<http://www.weforum.org/reports/global-enabling-trade-report-2012>. [1 August 2012].

Wilmsmeier, G., Hoffmann, J. and Sanchez, R. (2006) 'The impact of port characteristics on international maritime transport costs'. In Port Economics, Research in Transportation Economics, eds. K. Cullinane and W. Talley, Vol. 16, Elsevier, Amsterdam.

Wilmsmeier, G. and Martinez-Zarzoso, I. (2010) 'Determinants of maritime transport costs - a panel data analysis for Latin American trade', Transportation Planning and Technology, 33(1), pp. 105-121.

Wilson, J., Mann, C. L. and Otsuki, T. (2005), 'Assessing the Benefits of Trade Facilitation: A Global Perspective', The World Economy, 28(6), pp. 841-871.

Wilson, W. and Benson, D. (2009) Container Flows in World Trade, U.S. Waterborne Commerce and Rail Shipments in North American Markets. Available from: <http://trid.trb.org/view.aspx?id=1243491>. [18 June 2014].

World Bank (2012) Doing Business: Measuring Business Regulations. Available from: <http://www.doingbusiness.org/>. [1 August 2012].

Xu, M., Zhenfu, L., Yanlei, S., Xiaoling, Z. and Shufei, J. (2015) 'Evolution of regional inequality in the global shipping network', Journal of Transport Geography, 44, pp. 1-12.

xxx (2016). The authors 'blinded' the reference citation to accord with the anonymous peer review requirements. 